\title{
Design and Application of Scratch Personalized Learning Resources Based on VAK Learning Style Theory-Take Q School for Example
}

\author{
Wei Zhong \\ Nanjing Normal University, Nanjing, China \\ Email: 1324293546@qq.com
}

How to cite this paper: Zhong, W. (2019) Design and Application of Scratch Personalized Learning Resources Based on VAK Learning Style Theory-Take Q School for Example. Open Journal of Social Sciences, 7, 346-361.

https://doi.org/10.4236/jss.2019.78025

Received: July 24, 2019

Accepted: August 23, 2019

Published: August 26, 2019

Copyright $\odot 2019$ by author(s) and Scientific Research Publishing Inc. This work is licensed under the Creative Commons Attribution International License (CC BY 4.0). http://creativecommons.org/licenses/by/4.0/

\begin{abstract}
Students' ability varies, learning habits, personality characteristics and learning methods are also different in education and teaching, which leads to the traditional teaching methods are difficult to adjust. And it is difficult to teach students in accordance with their aptitude, students' learning is also lack of individuality and pertinence. And three themes of the contemporary education development are internationalization, informationization, personalized, in order to adapt to the trend of the Times, improve the efficiency of learning, let the students learn flexibly, promote their individual and comprehensive development. Based on the VAK learning style theory, this study designed Scratch learning resources to highlight personalization, so as to enable students to learn meaningfully and promote their personalized development.
\end{abstract}

\section{Keywords}

Scratch, VAK Learning Style, Personalized Learning Resources, Design, Application

\section{Introduction}

The arrival of the Internet age has brought new power to education and teaching. The emergence of micro-class, MOOC and flipped classroom has changed the classroom teaching mode and students' learning mode. More and more resources are available for students to use, but junior high school students' learning is still class-based, and learning resources are generally provided by schools or teachers, lacking pertinence and autonomy. However, students' learning habits, learning methods and learning purposes are not the same, which is not conducive to the efficient and flexible learning of students. Although teachers 
want students to reach their full potential, it is not realistic to tailor teaching methods to each student's aptitude under the traditional teaching model. However, reasonable educational resources should be able to help students learn, arouse students' interest in learning, and enable students to have targeted, independent and efficient learning. Therefore, it is very important to design personalized learning resources in line with students' physical and mental development. Internationalization, informatization and individuation have become three major themes in the development of contemporary education [1]. This study mainly focuses on "individuation" and takes Scratch as an example to develop and design learning resources based on VAK learning style theory.

\section{Research Status of Scratch Learning Resources}

Through literature analysis and organization, the author found that Scratch research status can be divided into foreign research status and domestic, and Hong Kong and Taiwan are the early introduction of Scratch in China, so China can be divided into Hong Kong and Taiwan and the mainland.

\subsection{Foreign Research Status}

There are abundant and in-depth researches on Scratch abroad. Scratch is mainly used in two aspects. First, Scratch is used to help children (over eight years old) learn programs, so that children can express themselves, stimulate their interests and experience collective cooperation and develop creative thinking in the learning process. Second, Scratch is used to guide students who have no basic knowledge to get started, so that they can feel that programming can be simple and interesting and learn in a relaxed and pleasant environment [2]. In addition, Scratch websites established abroad are mature and well resourced, allowing users to share their own works anytime and anywhere. However, there are few studies abroad that apply Scratch to formal learning in school classrooms. Most of the studies focus on students' programming ability, logical thinking ability and creativity [3].

\subsection{Domestic Research Status}

In 2008, Scratch was introduced into primary and secondary schools in Hong Kong, mainly to simplify students' learning process and make classroom learning more vivid and interesting on the basis of learning creative technology, so as to promote the long-term development of creative education in Hong Kong [4]. In Taiwan, Scratch is much richer. The main research aspects include the impact of Scratch on students' problem-solving ability, creativity and logical thinking ability by using experimental research and data analysis. For this purpose, Taiwan has established a Scratch communication and learning website, where students can share their own works and interact with teachers and other students [5].

The author took "Scratch" as the key word to conduct an accurate search in 
CNKI database, and found 5925 results. The main research contents include the following three aspects: first, in the classroom, Scratch was used as the learning content of information technology courses, and Scratch was simply taught to students. The second is to associate Scratch with "maker" and "maker education". Some of them develop Scratch teaching materials in the background of maker, or design Scratch courses based on "maker education" [6]. Third, in other disciplines, Scratch is used as an auxiliary tool to support teachers' teaching and students' learning. Through Scratch, lively learning resources are created to improve students' learning efficiency and improve classroom effect [7].

By analyzing and summarizing the literature, there has been little research on Scratch learning resource design, let alone personalized learning resources. The reason may be that Scratch is not difficult to learn and easy to learn, but this does not deny its great value [8]. In particular, Scratch ranked among the top 28 programming languages in TIOBE in May 2019, which further indicates its high popularity and usage worldwide.

Through the analysis of the resources on the Internet, it is found that the online learning resources still have shortcomings, and different kinds of learning resources are relatively independent design [9]. Most learning websites are just like a database, lacking the analysis of students' learning style and personality, and the personalized learning resources are almost blank. There are mainly two kinds of Scratch resources provided by Q school for students to learn Scratch: video tutorials on Scratch official website and text materials of traditional Chinese characters [10]. Besides, text materials still explain the knowledge points of old Scratch 1.4. At present, Q school is strengthening the construction of digital campus, paying more attention to Scratch teaching, and the learning effect and efficiency of students need to be improved. Q school is also looking for Scratch resources more suitable for students to learn.

\section{Research Ideas and Methods}

Based on the above status quo, the author will design Scratch learning resources that conform to the laws of physical and mental development of learners mainly according to the needs and characteristics of learners. In this design, personalized learning resources suitable for learners with different learning styles (Visual, Auditory and Operational) will be designed to make learners as the center and promote meaningful learning.

The service target of this resource is the first grade students of Q school. There are no exams in information technology courses, so students have less time to learn Scratch. Except for a few students who are interested in programming, most of them use class time to study. Therefore, the designed learning resources should be able to improve learners' learning efficiency in class and achieve better learning effect. And junior high school the students of grade one is still in the primary school to junior high school of transition, the awareness level is elementary school have a larger change, interest in boring things is not big, easy to produce resistance, learning environment and the elementary school and junior 
high school is different, so in the design of resources will pay attention to student's body and mind law of development, strive to resources can conform to the students' cognitive level, stimulate students' interest, to meet the curiosity of students to promote students' personal development. The content of the learning resources is mainly to Scratch the basic operation of the study, the types of resources mainly have three: image text tutorials, video tutorials, web learning operation, corresponding to three types of learners in the VAK learning styles: visual, auditory, operation, so the platform must first provide learners with VAK learning style online testing, after the test of the choice of resources accordingly again, at the same time it is also the embodiment of the "personalized" in this design.

The main research method is questionnaire survey. The researcher will provide the designed resources to the students of a class in the first grade of junior high school in Q school, and complete the relevant questionnaires after a period of study. The author mainly gets feedback from the questionnaire to understand the learning degree of the learning content, whether the learning efficiency has been improved, whether the platform interface is friendly and other related issues, and carries out reflection analysis and summary, and finally draws the conclusion.

\section{Scratch Personalized Learning Resource Design}

The learning resources of this study are for the first year students in Q school. Through observation during the internship, the author found that students' learning of knowledge was all completed in class, and few students took advantage of spare time to learn Scratch. However, information technology teachers provide students with unified learning resources in class, without considering the different learning characteristics of each student, and can only study according to the pace of teachers' lectures, which is not conducive to the personalized development of students. Although the country has put forward the requirements of promoting the comprehensive development of students, the current domestic classroom teaching is still not completely out of the shackles of traditional teaching, and in the current educational background, it is impossible to realize "one-to-one teaching" to teach students in accordance with their aptitude. Therefore, the design and production of this resource should not only highlight individuality, but also ensure that students can understand and master knowledge points through classroom learning. In order to facilitate learners' learning, the author will design and develop a website platform to collect three types of personalized resources on the platform, so as to improve the utilization rate of resources and learning efficiency.

\subsection{Resource Design Principles}

There are two types of resources in this design, one is image text resources suitable for visual learners, and the other is video resources suitable for auditory learners. The content of the knowledge points of the two types of resources is the 
same, but the way of expression is different, so the common design principles mainly include the following three points:

\subsubsection{Personalized}

Mentioned before, this paper has pointed out the personalized learning resources, based on respecting students' individual differences, cognitive difference and body and mind law of development as the prerequisite, and on the basis of certain after classifying students learning style theory, different types of learners choose different learning resources, improve the students' interest in learning content, and thus for the more effective learning, promote students' personalized development purposes [11].

The design of the resources mainly based on the theory of VAK learning style (Visual-Auditary-Kinesthetic learning styles), the learners are divided into three types: Visual, auditory, operation type (Kinesthetic), learning resources and the corresponding is divided into three types: image text, video tutorials, Scratch 2.0 web learning operation. Learners first conduct online test of VAK learning style on the platform, get their own learning style, and then choose the corresponding learning resources to start learning, so as to achieve personalization [12].

\subsubsection{Learner-Centered}

The new educational concept requires "learner-centered". In the design of resources, students' dominant position will be highlighted. As the master of the classroom, students use resources to study independently, while teachers' responsibility is to guide students to learn and think, and meanwhile, as the mentor of students' learning, help students solve problems. Teachers change the traditional classroom lectures students mode of the lectures, students use design good resources for independent learning, understand and master the knowledge points, and carries on the corresponding operation training. In the process, students can communicate with each other, solve the problem, if you have not solve the problem, help teachers, teacher as a student for answering questions again.

\subsubsection{Accord with Learners' Cognitive Level}

The design of this resource should be based on the actual situation of students. As an information technology course that does not require examination, students do not spend much time studying Scratch, mainly in the classroom [13]. Moreover, the first grade students are in the transitional period from concrete operation stage to formal operation stage, and have certain abstract thinking ability. Therefore, the design of resources should first ensure that students can understand and master relevant knowledge points in class, and the design of difficulty should conform to students' understanding level and the laws of physical and mental development

\subsection{Resource Content Design}

Given that junior year students are new to Scratch, the resources are focused on Scratch basics. A total of eight classes, using the form of a case system and a 
complete explanation of the operation of common function modules under the ten instructions, the content from simple to deep, step by step learning. Each class has three types of resources: visual, auditory, and operational (kinesthetic). Resources are classified on the platform, and learners can directly jump to the corresponding resources for learning after testing their learning styles. Among them, the picture text tutorial and video tutorial are both original design, web version operation learning is a built-in function of Scratch official website, and the whole platform is also original design.

Specific procedures: learners enter the Scratch personalized learning resource platform. If they know their own learning style, they can directly choose the corresponding resources to learn; otherwise, they will jump to the VAK learning style test page [14]. Learners get their own learning style after 24 questions, and then return to the home page to select the corresponding learning resources according to their own learning style. The results are visual, auditory, operational (kinesthetic), visual and auditory, visual and operational, auditory and operational, and possibly a combination of all three. Visual learners mainly learn by reading image text materials, and auditory learners mainly use video for learning. The aesthetic learners are also known as Kinesthetic learners, and then jump to Scratch 2.0 web page. Comprehensive learners, such as visual learners and auditory learners, can use image text materials and video for learning. They can choose only one of them, or they can use them crossingly. The overall content framework is shown in Figure 1.

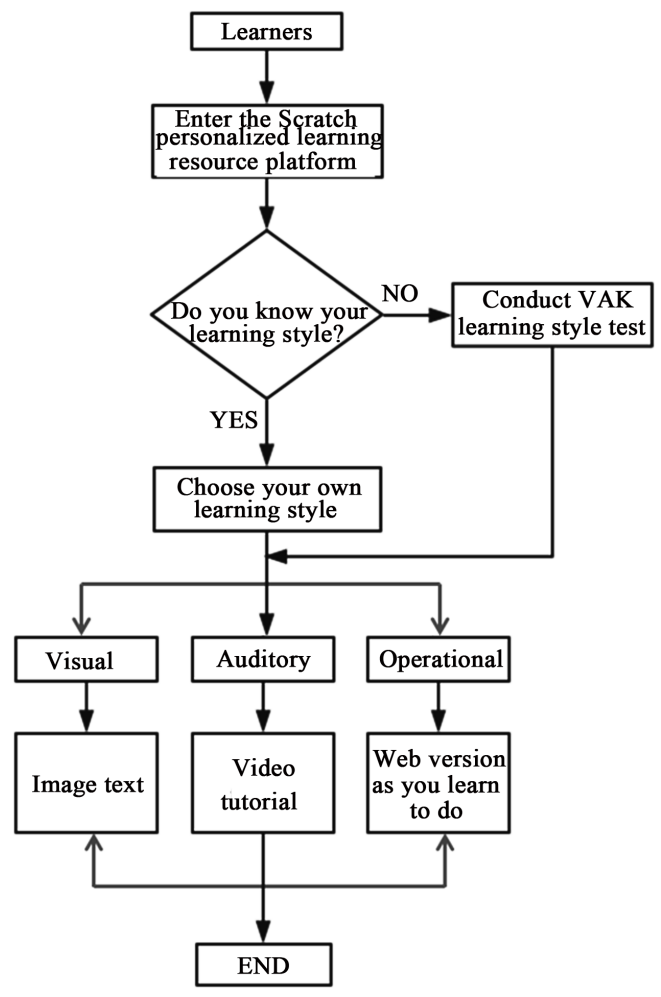

Figure 1. Overall content framework for scratch personalized learning resources. 


\subsection{Website Design Principles}

The learning resources of this design will take the web page as the carrier. In order to make the platform better serve learners, the website and its resources will be designed and developed according to certain principles, mainly including: [15].

\subsubsection{Clear Theme}

This website is Scratch personalized learning resource platform, content requirements design and production in strict accordance with the theme, the theme is clear, the web has strong interactivity, highlight the personalized design, resources will be different kinds of learning resources are assigned to different learning styles of learners use, improve the learning efficiency, and the content of the website are closely related topics, not creating relevant knowledge or other content.

\subsubsection{Combine the Needs of Learners}

Most of the students in grade one are between 12 and 14 years old. They are in the transitional period from children to young people. They like to pursue new things, and they still have children's curiosity, inquisitiveness and activity. Therefore, the design of the website mainly reflects individuation. It takes learners as the center and combines the specific needs of learners to provide learners of different learning types with learning resources in line with their own learning characteristics, learning habits and personality. Since learners mainly learn in class, the design of this platform and its resources should enable students to understand and master knowledge points in class.

\subsubsection{Uniform Style}

On the design of the web is always adhere to the principle of the style is unified, mainly reflected in the structure of system, the respect such as colour is tie-in, page layout, specifically, on the structure of web page design, the layout of the page, text layout, the style of the picture has high uniformity, and on the colour collocation, there are five main use of color: blue (\#199ED7), yellow (\#E1A91A), green (\#99CC00), purple (\#C2479D), red (\#BE1E2D), different functions of the main color page is different, the body of the website color matching.

\section{Technical Implementation of Scratch Personalized Learning Resource Platform}

In this study, three types of learning resources are centrally placed on the website, with the web page as the carrier. After the release, learners can directly start learning in the environment with network. Learners of different types should choose suitable learning resources after learning their own learning style. Among them, the online test of learning styles, picture and text resources (visual learners) and video resources (auditory learners) are self-made by the author, while the web version of learning resources (operational learners) is linked to 
Scratch 2.0 web version, that is, the author integrates and designs the resources on the Internet according to the types of learners.

\subsection{Platform System Function Realization}

The whole platform exists in the form of a website, and learners can learn online directly after release. The author mainly USES Adobe Dreamweaver CS5 software to design and make the website, and its page layout and system functions are mainly realized by simple HTML and CSS, and the layout and functions of the whole website are relatively simple. Site consists of six modules, respectively is "welcome (select) module", "online testing module", "visual learners module", "auditory learners module", "operation learners module", "navigation module", including the navigation module is divided into "VAK learning style introduction page", "explore page", "questionnaire" page, each module has one or more web pages below and by linking jump is entered, the main functions of the platform framework is shown in Figure 2.

\subsection{The Test Module of VAK Learning Style}

This module has only one page. If the learner does not know their own learning style, then skip to this page for online testing. Page content can be roughly divided into three parts, the first is a simple description of the test, the second part is the test instructions, the third part is 24 test questions. Each of these types has eight questions, arranged in a likert scale. There are five options for each question: always, usually, occasionally, rarely, never. The higher the score is, the more accustomed the learner is to the learning method. For example, visual > auditory > operation type, the type of learner is visual learner; if visual = auditory $>$ operation type, the type of learner is visual and auditory. After the tester fills in and submits, its learning type will appear directly, and then the learner selects the corresponding learning resources according to the results.

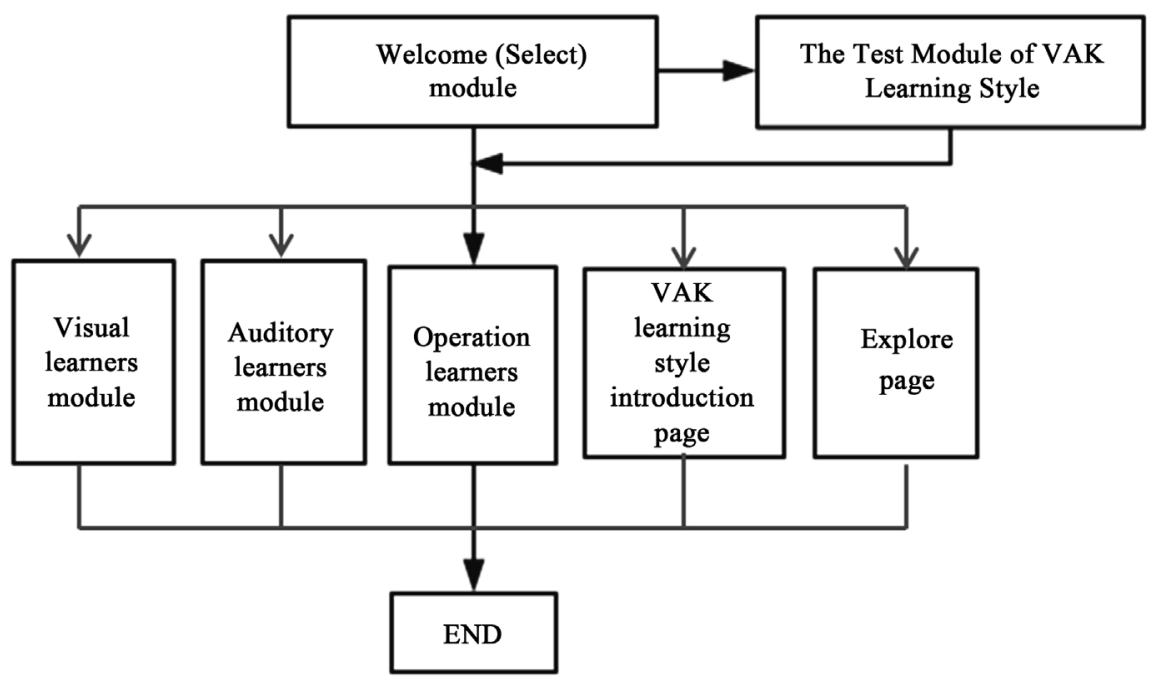

Figure 2. Scratch personalized learning resource platform functional framework. 


\subsection{Visual Learner Module}

Visual learners prefer to receive Visual stimulation in the learning process, and the learning resources provided for them are self-made picture text written reading materials. When learners click "visual learner" on the home page, they will jump to the visual module, which has 9 pages in total. After the jump, the first page to enter is the visual learner course catalog page, which is the main page of the module. There are two main parts of the content, the first is a simple introduction to visual learners and to provide resources for them; The second is the course catalog, which is presented in the form of pictures. There is one picture for each class. Click it to enter the study of course contents. Each course content page is mainly divided into three parts. The first is the effect gifs, which show the good project effects. Second, step directory, each step corresponds to an operation, click can directly jump to the corresponding specific operation; Third, the complete content of this lesson. The page of this module is also designed and produced with Adobe Dreamweaver CS5, and its content is produced in Adobe Photoshop CS5 to synthesize related images and text.

\subsection{Auditory Learner Module}

Auditary learners like to listen to the teacher and are accustomed to receiving sound stimulation. The learning resource provided for them is video self-made by the author. Learners in the home page, click on the "auditory learners", will jump to auditory module, the module of a total of nine pages, after the jump into the above all are visual learners course catalog page, that is the main page of the module, its contents and related links is similar to the "visual learners", eight other pages are respectively each lesson video.

\subsection{Operational Learner Module}

Operation learners (Kinesthetic) prefer to learn by hands-on experience, so it would jump directly to Scratch 2.0 web version

(https://scratch.mit.edu/projects/editor/?tip bar=home), whose learning resources are from Scratch's official website. The course content is the same with the other two types. Operational module only web page version of a page, on the front page select "operation learners" after the jump straight into the web version of the study, the main page is divided into two parts, the left side is the web version of the Scratch, the operating interface and offline client versions have the same function, learners will be directly used to make the project, the right can open a small window, embedded inside is curriculum resources, so that learners can operation to learn while I watched the resource, realize "synchronization".

\subsection{Navigation Module}

The first is the "introduction page of VAK learning style", which is designed and produced by the author himself. The main content is to introduce the theory of the style and provide learning Suggestions for each type of learners. Learners can learn about the learning style before testing. Visual learners are accustomed to 
learning and memorizing by "seeing". They like to receive visual stimulation, like graphics, pictures and reading written materials. Therefore, visual learners are provided with learning resources combining text and pictures. Auditory learners prefer to receive sound stimulation and learn by "listening" in the learning process. They like to listen to teachers' lectures. The learning strategies they usually choose are listening to lectures and listening to video and so on. Operational learners, also known as kinesthetic learners, prefer to learn through "physical" contact and hands-on practice, so the learning resources for operational learners will jump directly to the web version of Scratch and learn through operation. "Explore" page is directed

(https://scratch.mit.edu/explore/projects/all) connected to the network, the page is also a Scratch under the official website of a page, here there are many Scratch users upload project and work, games, animation, stories, music, etc. , each work can jump to the application page, see the effect is how to implement, can also work for secondary revision, join your ideas and thoughts, it provides learners with the opportunity to learn more. The next step is "questionnaire survey". Click it and jump directly to the questionnaire page. The author enters the contents of the questionnaire into the questionnaire star.

\section{Analysis of Application Effect of Scratch Personalized Learning Resources}

This part mainly analyzes the application effect. The author provided the prepared resources to the students of class 2, grade 1 (48 students) and class 5, grade 1 (50 students) of Q school, and then the students filled in the questionnaire according to their own learning and experience (Appendix). The author mainly evaluates and reflects on the learning resources through the statistics and analysis of the questionnaire results. The author put the completed questionnaire on the platform, and the learners filled in the questionnaire directly online after learning, and finally received 88 valid questionnaires.

\subsection{Analysis of Resource Content}

Through sorting out and analyzing the questionnaire, it is found that $10.23 \%$ of the learners have never learned Scratch before, and $53.41 \%$ of them are just beginning to learn Scratch and only know a little basic operation. $97.73 \%$ of learners believe that they have deepened their understanding of Scratch through learning on this platform and found a suitable way to learn Scratch. $97.73 \%$ of learners prefer this personalized learning method to previous classroom teaching. $96.59 \%$ of the learners think that they have increased their interest in learning Scratch through this personalized learning platform.

Based on the above data analysis, it can be found that the use of the platform is good. Learning resources are designed and integrated according to learners' needs and personality characteristics, and learners are allowed to choose their own learning methods through tests, which is conducive to learners' mastery and understanding of knowledge points, and enables learners to become the 
main body of the classroom and learn independently. Teachers, as their mentors, guide students to learn. In this process, it is helpful for students to learn independently, pertinently and flexibly, and stimulate students' interest in learning so as to promote their meaningful learning.

\subsection{Analysis of Platform Design}

In terms of the design and layout of the platform, learners are quite satisfied. $96.59 \%$ of learners think that the website is simple, friendly and efficient. Only $3.41 \%$ of learners believe that the content design of this resource does not meet their cognitive level. $96.59 \%$ of learners think that the page layout on the platform is simple and beautiful, which conforms to their aesthetic level. Based on the analysis of the above data, learners are satisfied with the appearance of the platform, with strong interaction, simple and convenient operation, which is conducive to their learning.

\subsection{Analysis of Learning Efficiency}

$96.59 \%$ of learners believe that the resources on this platform are conducive to their understanding and mastery of knowledge points. Only $2.27 \%$ of learners think that this platform has not improved their learning efficiency. $97.73 \%$ of learners believe that through learning on this platform, they can understand and master the knowledge points in class. Only $2.27 \%$ of learners think this personalized learning resource is not suitable for their own learning. $96.59 \%$ of the learners think that they have increased their interest in learning Scratch through this platform.

Based on the analysis of the above data, the design of personalized resources has achieved the goal of improving students' learning efficiency. The emergence of resources also alleviates teachers' teaching tasks and makes teachers more targeted in preparing lessons. And students learn more flexibly and efficiently in the classroom. To sum up, the design of this resource is quite successful. After learning on the platform, learners will submit their own works, as shown in Figure 3.
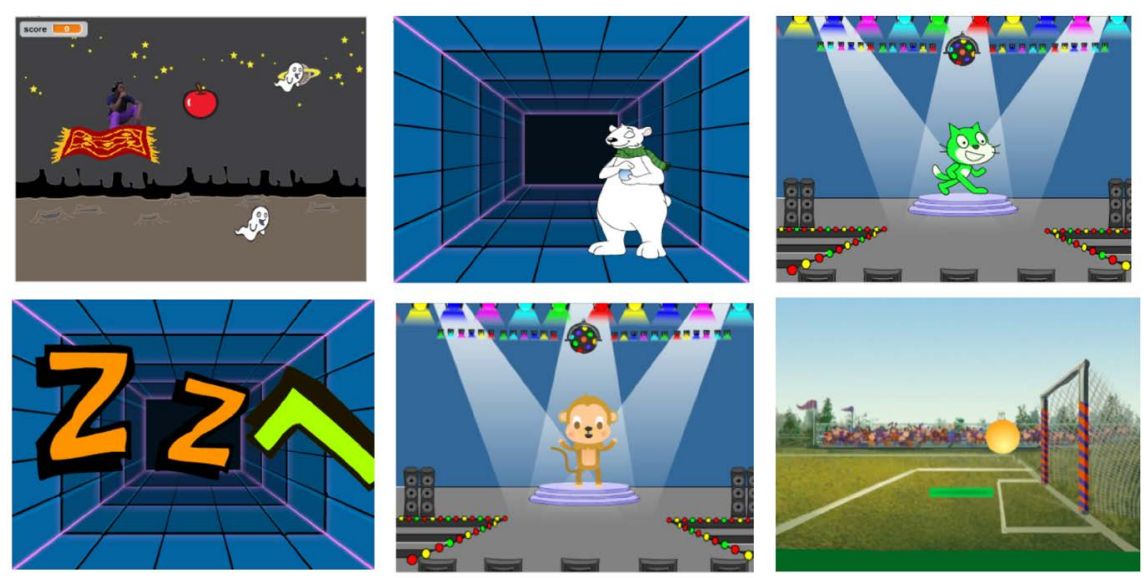

Figure 3. Student work. 


\section{Summary and Prospect}

This paper takes the students from Class 2 and Class 5 of Grade 1 of Q school as the research object, designs and implements the Scratch personalized learning resource platform by designing and integrating excellent learning resources on the Internet and combining the specific needs of the research object.

\subsection{Platform Advantages}

The author had a two-month internship in Q school before and had some understanding of the previous classroom situation of learners. After learning with Scratch personalized learning resource platform, the author found through research that this platform has the following advantages compared with traditional teaching methods:

\subsubsection{Improve Learners' Interest in Learning}

Whether through the author's observation in class or the feedback from $\mathrm{Q}$ school teachers and students, it can be found that learners' interest in learning is greatly improved by using this platform. As mentioned above, first-grade students are easy to accept new things, and are curious about new things and willing to explore. Therefore, different from the traditional classroom learning mode, this platform stimulates their curiosity and thirst for knowledge, and their enthusiasm for creation increases accordingly. In the class, each student used the platform to study and created his own works. Some students submitted more than one work, and the learning atmosphere of the whole class was high.

\subsubsection{The Concept of "Learner-Centered" Is Realized}

In the process of learning, learners learn independently according to learning resources, students create freely in the whole class, and teachers are only the mentors and helpers of students. When learners encounter problems, they can use resources to repeat learning, or discuss independently. If they cannot solve the problems, teachers will explain them. In the process of using resources to learn, learners will also divergent thinking to create. Through observation, the author finds that learners enjoy the process of creation. Although the case contents provided are the same, the works created by students are different from each other. Some students increase their own ideas and ideas on the basis of the original, and constantly improve the works.

\subsubsection{Conducive to Teachers' Control and Management of Class}

As an intern in $\mathrm{Q}$ school, our intern teacher did not do a good job in class control and management. There are two main reasons: one teaching experience is not enough, two do not understand the level of students. After students use this platform to study, students with strong learning ability will take the initiative to learn the following content after completing the task, and will do nothing as before, so that the classroom discipline is much better. After completing the classroom tasks, students can also go to the exploration page to learn more know- 
ledge. Therefore, this platform can meet the needs of students of different levels, so that teachers only need to solve the problems in students' learning, and do not spend too much time to manage classroom discipline.

\subsection{Research Prospects}

Through the author's research and practice, this research has achieved some positive results, but the design and application of personalized learning resources are still in the exploration stage, and there are still many aspects to be improved. Based on the actual situation of this study, the author thinks that the follow-up research can be carried out from the following aspects.

Firstly, there is no doubt to increase the sample size and practice time. In other words, the platform will be put into more classes, so that the data obtained will be closer to the real situation and the conclusions will be more general and less individual. Secondly, big data technology can be used for comprehensive analysis and testing of learners to obtain more reliable results, so as to push personalized learning resources to learners. The function of sharing works and communication can be added on the platform to provide a space for learners to display and stimulate their creativity.

The three major themes of contemporary education development are internationalization, informatization and individuation, and the new educational concept also requires "student-centered". Nowadays, personalized learning is rising and developing, and more and more research on it. The rise of personalized teaching provides the possibility for the emergence of new teaching mode, and also allows us to see more possibilities of education and teaching. Through this research, we find that making students the subject of learning and providing resources suitable for the development of students' personality characteristics can not only stimulate their interest in learning but also help improve their learning efficiency. This fully proves that personalized learning can promote learners' learning. But most research has been limited to textual descriptions, and very few have been successful. Therefore, there is still a long way to go for the research and practice of "personalized learning", which requires more and constant practice and innovation. The arrival of the era of big data provides more possibilities for personalized learning. This design is just an attempt, hoping to develop more learning content on this basis in the future, build a more perfect personalized learning resource platform, bring greater convenience and benefits to students' learning, and make students' learning more free, flexible and personalized.

\section{Conflicts of Interest}

The author declares no conflicts of interest regarding the publication of this paper.

\section{References}

[1] Zhang, H.Y. (2014) Research on the Application of Micro-Curriculum in Scratch 
Teaching in Primary Schools. Shanghai Normal University, Shanghai.

[2] Wang, X.X. (2012) Application Research of Scratch in Program Design Teaching in Middle School under Network Environment. Southwest University, Chongqing.

[3] Wang, B.L. (2015) Research on the Application of Scratch in Junior Middle School Information Technology Teaching. Central China Normal University, Wuhan, 5.

[4] Dong, J.W. (2016) Research on the Construction of Personalized Learning System. East China Normal University, Shanghai, 4.

[5] Ma, Y. and Chen, Y.X. (2013) Construction of English Multimedia Network Independent Learning Model Based on VAK 3d Learning Style Theory. Education and Teaching BBS, No. 117, 180-181.

[6] Li, G. and Jiang, Y.J. (2005) Theoretical Construction and Characteristic Analysis of Personalized Learning. Journal of Northeast Normal University, No. 3, 152-156.

[7] Cao, X.M. and Zhu, Y. (2014) Research on Personalized Learning Platform from the Perspective of Learning Analysis. Open Education Research, 20, 67-74.

[8] Yang, Y.Q. (2014) Construction of Personalized Learning Model for MOOC Learners. China Audio-Visual Education, No. 329, 6-10.

[9] Li, B. and zhang, W.L. (2015) Construction of Push Service Model of Learning Resources in Intelligent Education. Journal of Distance Education, 33, 43-50.

[10] Wang, Q. (2015) Scratch Based Information Literacy Training of Middle School Students. Shaanxi Normal University, Xi'an.

[11] Jin, Y.J. (2014) Development, Research and Practice of School-Based Teaching Materials in the Context of Makers. Shanghai Normal University, Shanghai.

[12] Liu, S. (2013) Chinese Teaching Design in Brunei Primary Schools from the Perspective of Differential Teaching. Northeast Normal University, Changchun.

[13] Chang, Y.H. (2018) Research on Differential Teaching Design Based on Scratch Expansion Course. Shanghai Normal University, Shanghai.

[14] Xu, X.X. (2019) Practical Exploration of Primary English Teaching Based on VAK Teaching Model. Learning Weekly, No. 19, 152.

[15] Shi, J.Y. (2019) User Experience Optimization of Web Interface Design. In: CPC Shenyang Municipal Committee, Shenyang People's Government, International Academy of Production Engineering, China Institute of Mechanical Engineering, Eds., Papers of the 16th Annual Conference of Shenyang Science (Economic and Social Science), CPC Shenyang Municipal Committee, Shenyang People's Government, International Academy of Production and Engineering, China Machinery Engineering Society, Shenyang Association of Science and Technology, Shenyang, 4. 


\section{Appendix}

\section{Scratch Personalized Learning Resource Platform Use Questionnaire}

Dear classmates:

Hello!

First of all, thank you very much for using Scratch personalized learning resources platform for learning. The main purpose of this survey is to understand your learning situation using this platform and your satisfaction with learning resources. There are no right or wrong questions. Please fill in the true feelings of use. We will keep your information strictly confidential. Please feel free to fill in. Thank you very much.

1) Gender

A. man

B. woman

2) What is your learning style?

A. Visual type

B. Auditory type

C. Operational type

D. Visual and auditory

E. Visual and operational

F. Auditory and operational

G. Visual, auditory and operational

3) Have you ever studied Scratch before? How much did you learn?

A. Learned it; familiar with Scratch, you can create your own works

B. Learned; basic operations are all metropolitan.

C. Learned; just started, only a little bit.

D. Not learned

4) Do you think the resources on this platform will help you understand and master the knowledge points?
A. is
B. General
C. no
5) Do you think this platform can improve your learning efficiency?
A. is
B. General
C. no
6) Through this study, do you know more about yourself and find a suitable way of learning?
A. is
B. General
C. no

7) Compared with the previous classroom teaching, do you like this personalized learning method?

A. is 
B. General

C. no

8) Does the design of resource content meet your cognitive level?

A. is

B. General

C. no

9) Has this learning resource design increased your interest in learning Scratch?
A. is
B. General
C. no
A. is
B. General
C. no

10) Is the operation on this platform simple, friendly and efficient?

11) Is the layout of the pages on this platform concise and beautiful, in line with your aesthetic level?
A. Yes
B. General
C. No

12) Through this platform, do you understand and master the knowledge of this lesson in class?
A. Yes
B. General

C. No

13) Do you think the personalized resources designed by this platform are suitable for you to learn?
A. is
B. General
C. no 